\title{
Limites e oportunidades para a construção de um Arranjo Produtivo Local (APL): a experiência do projeto Balde Cheio em Mato Grosso do Sul
}

Limits and opportunities for building a Local Productive Arrangement (APL): the experience of the "Balde Cheio" project in Mato Grosso do Sul state Limites et possibilités pour la création d'un Arrangement Productif Localisé (APL): l'expérience du projet du projet "Balde Cheio" dans l'état de Mato Grosso do Sul

Límites y oportunidades para la creación de un Arreglo Productivo Local (APL): la experiencia del proyecto "Balde Cheio" en el estado de Mato Grosso do Sul

\author{
Lilian Cervo Cabrera ${ }^{1}$ \\ Glauco Schultz ${ }^{1}$ \\ Edson Talamini ${ }^{1}$
}

Recebido em 03/02/2017; revisado e aprovado em 17/04/2017; aceito em 19/05/2017

DOI: http://dx.doi.org/10.20435/inter.v18i4.1484

\begin{abstract}
Resumo: Neste trabalho, é analisado se o Projeto Balde Cheio, em Mato Grosso do Sul, pode direcionar para a caracterização de um Arranjo Produtivo Local (APL), apontando limitações e potencialidades para sua construção. Quanto aos aspectos metodológicos, utilizaram-se dados secundários mediante pesquisa bibliográfica e pesquisa de campo com visita em propriedades rurais. A disponibilidade de capacitação técnica, o apoio financeiro do Estado, o aumento da produção/produtividade de leite nas propriedades, entre outros, são elementos que podem direcionar para um APL.
\end{abstract}

Palavras-chave: cadeia produtiva do leite; agricultura familiar; transferência de tecnologia.

Abstract: The aim of the current study is to analyze whether the "Balde Cheio" (Full Bucket) Project, which is carried out in Mato Grosso do Sul State, may lead to a Local Productive Arrangement (APL) pointing out limitations and potentialities for its construction. As the methodological aspects, we used secondary data through literature and field research (visit farms). The technical training availability, the financial support given by the State, and the increased milk production/productivity in the properties are elements able to lead to the LPA.

Key words: milk production chain; family farming; technology transfer.

Résumé: Cet article analyse si le Projet "Balde Cheio" (Seau Rempli), développé dans l'État de Mato Grosso do Sul, peut caractériser un Arrangement Productif Localisé (APL), montrant les limites et les possibilités de sa construction. Comme les aspects méthodologiques, nous avons utilisé des données secondaires grâce à la recherche de la littérature et sur le terrain pour visiter les fermes. La disponibilité de la qualification technique, le soutien financier de l'État et l'augmentation de la production/productivité du lait dans les propriétés sont des éléments qui peuvent caractériser un APL.

Mots-clés: la chaîne de production de lait; l'agriculture familiale; le transfert de technologie.

Resumen: En este trabajo se analiza si el Proyecto "Balde Cheio" (Balde Lleno), en Mato Grosso del Sur, puede direccionar para la caracterización de un Arreglo Productivo Local (APL), señalando las limitaciones y el potencial para su construcción. Como los aspectos metodológicos, se utilizaron los datos secundarios a través de la literatura y la investigación de campo para visitar granjas. La disponibilidad de capacitación técnica, el apoyo financiero del Estado, el aumento de la producción/productividad de leche en las propiedades, entre otros, son elementos que pueden direccionar para un APL.

Palabras clave: cadena productiva de leche; agricultura familiar; transferencia de tecnología.

\footnotetext{
${ }^{1}$ Universidade Federal do Rio Grande do Sul (UFRGS), Porto Alegre, Rio Grande do Sul, Brasil.
} 


\section{INTRODUÇÃO}

O consumo de leite tem crescido no Brasil e no mundo, mas a produção leiteira em Mato Grosso do Sul tem aumentado timidamente. De 1990 a 2010, o Estado cresceu apenas 28,07\% em termos de produção de leite, enquanto o Brasil cresceu 118,6\% e o Centro-Oeste $158,8 \%$ (IBGE, 2014). No período de 2010 a 2014, a produção aumentou de 506.044 milhões para 528.738 milhões de litros de leite, o que representa apenas 4,3\% de crescimento (IBGE, 2014). Entre os motivos para esse pequeno crescimento, estão a pouca qualificação do produtor e o baixo preço pago pelo produto (MICHELS et al., 2003; BACARJI; SAUER, 2011). Frente a esses problemas, verifica-se a necessidade de ações que impulsionem o setor a buscar maiores índices de produção e produtividade, bem como incentivar a agroindústria a agregar valor ao leite produzido no Estado.

Desse modo, este trabalho tem por objetivo analisar em que medida o Projeto Balde Cheio pode funcionar como vetor de formação de um Arranjo Produtivo Local (APL), destacando potencialidades e fragilidades do Projeto. O Projeto Balde Cheio tem como objetivo promover o desenvolvimento da pecuária leiteira, mediante o processo de transferência de tecnologias já disponíveis, para extensionistas de entidades públicas ou privadas, bem como para produtores de leite. O Projeto vem sendo implantado no Estado de Mato Grosso do Sul, mais especificadamente no município de Sidrolândia, desde 2009.

A partir da caracterização do Projeto Balde Cheio em Mato Grosso do Sul, busca-se relacionar a abordagem teórica de Arranjos Produtivos Locais (APL) com as ações e objetivos do Projeto. Inicialmente apresenta-se a caracterização da produção leiteira no Estado e as potencialidades locais para o desenvolvimento da atividade no município. Em seguida, descrevem-se os procedimentos adotados pelo projeto em questão e, por fim, as contribuições dele para a caracterização de APL.

\section{OS ARRANJOS PRODUTIVOS LOCAIS (APL)}

Arranjos Produtivos Locais (APL) podem ser entendidos como um conjunto de atividades econômicas que possuem certo vínculo de produção, interação, cooperação e aprendizagem e que podem ser desenvolvidos por aglomerações territoriais de agentes políticos, econômicos e sociais (AMATO NETO, 2009). Büttenbender (2010) amplia esse conceito e define-os como rede de relações sociais que se projetam em um determinado espaço cuja dimensão construtiva é econômica por definição, apesar de não se restringir a ela. Para Costa e Costa (2005), esse arranjo caracteriza-se por apresentar um produto representativo, em torno do qual se desenvolvem atividades subsidiárias de montante a jusante.

Para Noronha e Turchi (2005), a essência da definição de APL está na especialidade da produção e na delimitação espacial. Segundo esses critérios, qualquer concentração de um tipo de produção, seja em uma região, município, bairro ou mesmo rua, pode ser denominada APL. Extrapolando ainda mais os conceitos abordados acima, seria possível concluir que qualquer aglomeração de empresas, em território geográfico não definido, que desenvolvam atividades econômicas nos setores primário, secundário ou terciário, poderia ser considerada um APL. Para Lastres e Cassiolato (2003), os APL são caracterizados por uma dimensão territorial; por uma diversidade de atividades e atores econômicos, políticos e sociais; por um conhecimento tácito; por inovação e aprendizado interativos; por governança e por um grau de enraizamento. Desse modo, o desenvolvimento dos APL depende das relações entre os seus atores e da cooperação 
entre eles. Frente a isso, o papel do setor público é criar políticas que auxiliem o desenvolvimento de APL, desde o desenvolvimento da infraestrutura até a comercialização dos produtos. Através de políticas governamentais, o governo exerce um papel fundamental no fortalecimento dos APL. No Brasil, a base dos APL parte de políticas públicas de desenvolvimento que tem por intuito promover a ascensão econômica e social. O governo pode ter várias funções: (i) gerar infraestrutura que apoie o crescimento dos APL; (ii) auxiliar o ensino e treinamento da mão de obra; (iii) apoiar centros de pesquisa e desenvolvimento; (iv) financiar investimentos; (v) realizar investimentos públicos que possibilitem condições para o crescimento dos APL (RIBEIRO et. al., 2013). Assim, os APL podem atuar como impulsionadores da economia e do desenvolvimento local.

A exposição feita aqui dos conceitos de APL é extremamente breve, não há a pretensão de revisar todos os autores e abordagens, pois não caberia no escopo e nas intenções deste trabalho. O intuito é apresentá-los de modo a possibilitar sua compreensão e relacioná-los com o projeto analisado.

\section{CARACTERIZAÇÃO DA PRODUÇÃO LEITEIRA EM MATO GROSSO DO SUL}

Mato Grosso do Sul contém oito bacias leiteiras: as bacias do Cone Sul, de Nova Andradina, de Glória de Dourados, de Dourados, de Aquidauana, de Campo Grande, do Centro-Norte e a bacia do Bolsão, conforme mostra o mapa da Figura 1. Segundo a Secretaria de Estado de Meio Ambiente, Desenvolvimento Econômico, Produção e Agricultura Familiar (SEMAGRO)., para a subdivisão foram utilizados dois critérios principais: a homogeneidade dos produtores no uso de tecnologia e o local da comercialização do leite, no Estado ou em outros Estados. O município de Sidrolândia pertence à Bacia de Campo Grande.
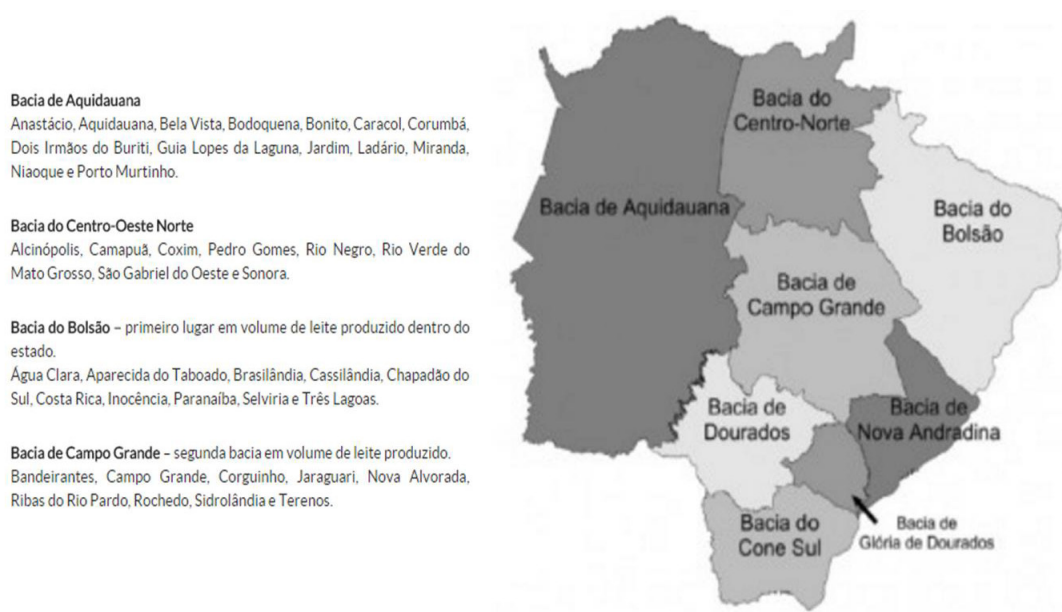

Bacia de Nova Andradina Parrourilandia, Bataguarusu

Bacia de Glória de Dourados

Angélica, Deodápolis, Fátima do Sul, Glória de Dourados, Ivinhema, Jateí, Novo Horizonte do Sul e Vicentina

Bacia do Cone Sul

Amambai, Aral Moreira, Coronel Sapucaia, Eldorado, Iguatemi, Itaquirà, Japoråa, Juty, Mundo Novo, Navirai, Paranhos, Sete Quedas e Tacuru.

Bacia de Dourados

Antônio Joåo, Caarapó, Dourados, Douradina, Itaporă, Laguna Caarapă, Maracajú, Ponta Poră e Rio Brilhante. Ribas do Rio Pardo, Rochedo, Sidrolândiae Terenos.

Figura 1 - Mapa do estado de Mato Grosso do Sul: destaque para as bacias leiteiras do Estado Fonte: Mato Grosso do Sul (s.d.)

Os produtores do Estado caracterizam-se por terem baixo nível de informação, produção não-especializada, baixa produtividade e pequenos volumes de produção. Além disso, a grande maioria utiliza-se de financiamentos para a aquisição de animais, investimentos e custeio. Poucos são vinculados a associações ou cooperativas para a comercialização do produto (MICHELS et al., 2003). 
Segundo dados do Censo Agropecuário 2006, a atividade leiteira é a terceira maior atividade econômica de Mato Grosso do Sul, que ocupa o décimo segundo lugar na classificação nacional, sendo o terceiro maior produtor da região Centro-Oeste (IBGE, 2009). O Estado produz aproximadamente 491 milhões de litros de leite, e a produtividade média do rebanho é de 3 litros/vaca/dia. Além disso, a pecuária leiteria é essencialmente uma atividade de pequenos produtores, uma vez que mais de $50 \%$ do leite produzido em Mato Grosso do Sul é proveniente de propriedades com menos de 50 hectares. Aproximadamente $56 \%$ do leite produzido no Estado é oriundo de propriedades de agricultura familiar, e a atividade leiteira emprega em torno de $35 \%$ da força de trabalho do campo.

Desse modo, apesar de ter um dos maiores rebanhos do país, Mato Grosso do Sul apresenta baixa produtividade de leite, cerca de 1000 litros/ha/ano. Isso ocorre principalmente por existir a predominância de genética de gado de corte no Estado e de um sistema misto de produção (leite e carne), pelo manejo inadequado das pastagens, pelo manejo de desmama inadequado (típico de gado de corte), pela realização de apenas uma ordenha por dia, pela falta de cuidados na higiene na ordenha e pela falta de informações gerenciais das propriedades rurais para tomada de decisão (SIMÕES, 2009). No entanto todos estes são fatores que podem ser revertidos com maior investimento em transferência tecnológica apropriada à produção de leite.

\section{METODOLOGIA}

Para este trabalho, foi realizada uma pesquisa exploratória e bibliográfica do Projeto Balde Cheio em Mato Grosso do Sul. A primeira etapa do trabalho foi a de aproximação com os conceitos de APL e os autores que pesquisam sobre o tema. Para a pesquisa bibliográfica, utilizaram-se, principalmente, dados secundários.

Em uma segunda etapa, foram feitas visitas a propriedades agrícolas que participavam do Projeto em Sidrolândia, com o propósito de acompanhar as atividades do dia a dia e conversar com os agricultores sobre o Projeto Balde Cheio. As visitas foram acompanhadas pelo secretário de desenvolvimento rural do município.

A terceira etapa foi a de análise teórica, com o objetivo de interpretar a proximidade ou distanciamento das situações verificadas no campo com os conceitos definidos na teoria. Como há pouco conhecimento acumulado e sistematizado sobre o Projeto, buscou-se, a partir da teoria existente, elaborar suposições e hipóteses para um setor com potencial para crescimento no Estado. Além disso, dois especialistas foram consultados com o objetivo de obter mais informações sobre o Projeto: o coordenador técnico local da AGRAER e o coordenador do Projeto em Mato Grosso do Sul. A partir dessas etapas da pesquisa, objetivou-se descrever, a partir do Projeto, as oportunidades e as limitações para a construção de um APL no Estado.

\section{O PROJETO BALDE CHEIO EM MATO GROSSO DO SUL}

Como estratégia para melhorar a cadeia produtiva de leite do Estado, o Governo do Estado, junto com a Federação da Agricultura de Mato Grosso do Sul (FAMASUL), a Secretaria de Estado de Desenvolvimento Agrário, da Produção, da Indústria, do Comércio e Turismo (SEPROTUR), o Instituto Nacional de Colonização e Reforma Agrária (INCRA) e a Agência de Desenvolvimento Agrário e Extensão Rural (AGRAER) firmaram parceria para a implantação do Projeto Balde Cheio. 
O Projeto Balde Cheio tem como objetivo promover o desenvolvimento sustentável da pecuária leiteira na região de atuação, via transferência de tecnologia ao extensionista e, em seguida, ao produtor rural. Para isso, utiliza a metodologia de transformar uma propriedade leiteira de cunho familiar em "sala de aula prática", denominada UD (Unidade de Demonstração), onde o conhecimento de todos os envolvidos (pesquisadores, extensionistas e produtores) é atualizado. A partir da implantação do Projeto, a UD passa a ser uma referência na região, permitindo que outros produtores acompanhem o trabalho de viabilização da produção de leite sob vários aspectos: técnico, econômico, social e ambiental (EMBRAPA, 2011). O Projeto foi criado pelo pesquisador Arthur Chinelato e é acompanhado pela Embrapa Pecuária Leste naqueles locais em que houver convênios para realização da assistência técnica aos produtores de leite, seja com empresas lácteas, administrações municipais ou estaduais e associações de produtores de leite.

\section{DETALHAMENTO DO PROJETO NO ESTADO}

Em Mato Grosso do Sul, o Projeto vem sendo implantado desde 2007, em diversos municípios do Estado. Foi feito um convênio com o Governo do Estado, através da AGRAER, e com o acompanhamento da Embrapa. Os produtores rurais de São Gabriel do Oeste foram os primeiros a fazer parte do Projeto, que vem sendo desenvolvido por técnicos e extensionistas da AGRAER.

As primeiras atividades realizadas pelos técnicos da AGRAER foram visitas a propriedades rurais localizadas no interior de São Paulo, onde o Projeto é desenvolvido por meio da Coordenadoria de Assistência Técnica Integral do Estado de São Paulo (Cati, SP). Participaram das visitas cerca de 70 técnicos. As visitas serviram para que os técnicos conhecessem o Projeto na prática. A partir das excursões, cada técnico fez uma avaliação do seu município, buscando características que permitissem o desenvolvimento do Projeto.

A metodologia do Projeto consiste basicamente em selecionar uma propriedade pelo extensionista, devendo preferencialmente ser de pequeno porte (a partir de 0,5 hectare), ter na atividade leiteira sua principal fonte de renda e ser de cunho familiar. Selecionada a propriedade, a visita de um instrutor credenciado pelo Projeto Balde Cheio ocorre a cada quatro meses durante quatro anos (tempo do Projeto), totalizando doze visitas de acompanhamento. Nessas visitas, além do instrutor credenciado, estão presentes o extensionista responsável pela UD e o produtor rural. O extensionista responsável visita a UD na frequência mínima de uma vez por mês (EMBRAPA, 2011).

A propriedade que se torna uma UD deve cumprir algumas obrigações, como realizar, de imediato, exames para detecção de brucelose e tuberculose, permitir que sua propriedade seja visitada por outros produtores e outros técnicos e anotar controles básicos relativos ao clima (chuvas e temperaturas máxima e mínima), às finanças (despesas e receitas com a atividade leiteira) e ao rebanho (parições, coberturas, pesagens mensais de fêmeas em crescimento e controles leiteiros) (EMBRAPA, 2011).

No município de Sidrolândia, o Projeto teve início em 2009, primeiramente por meio da capacitação de produtores rurais. Essa capacitação teve o objetivo de viabilizar equipamentos e instrução técnica aos produtores nos assentamentos para dinamizar e aperfeiçoar a produção leiteira do município. Os técnicos da AGRAER destacaram os principais cuidados que devem ser tomados com o animal, a utilização de equipamentos e o acondicionamento do leite, que envolve fatores como a umidade, temperatura e luminosidade do local. 
Um dos principais objetivos do Projeto Balde Cheio é a melhoria da pastagem, com adubação e irrigação, a rotação de animais na área, a melhoria genética e o aumento da produtividade com ênfase na qualidade da alimentação do animal. Em 2010, iniciou-se no município a plantação da pastagem tifton (Cynodon spp.) nas propriedades que participam do Projeto. O Projeto prevê dois pastos rotacionados, um de capim-mombaça (Panicum maximum cv. Mombaça) e outro de tifton, os quais garantem a comida dos animais em piquetes. Na época de estiagem, a alimentação das vacas é complementada com cana-de-açúcar (Saccharum officinarum) servida no cocho aos animais. A raça aconselhada pelos técnicos da AGRAER para a criação na região é a Girolando (um cruzamento entre as raças de gado gir e holandesa), uma vez que esta apresenta a rusticidade do gir e a produtividade do holandês, qualidades necessárias para a produção leiteira no Centro-Oeste. Para cada hectare de pastagem, pode-se criar até oito vacas.

Sidrolândia concentra, em seu território, cinco mil pequenas propriedades e encontra-se em uma região privilegiada, devido à proximidade com grandes centros consumidores, notadamente Campo Grande, a capital do Estado. Atualmente, a bacia leiteira do município mobiliza aproximadamente mil pequenos produtores, que colocam no mercado aproximadamente 10 mil litros diários, com potencial para aumentar esse volume três vezes (30 mil litros). Além disso, em relação à comercialização, a instalação de um laticínio no município de Terenos (com capacidade diária para processar 650 mil litros de leite) e as indústrias dos municípios de Dourados, Campo Grande, São Gabriel e Rio Brilhante proporcionam um equilíbrio entre a oferta e a demanda do produto na região.

Diante dos fatos, o Estado apresenta-se como um dos mais promissores no desenvolvimento da produção leiteira nacional, visto suas potencialidades. Tem um dos maiores rebanhos do País e encontra-se inserido no novo circuito de produção leiteira, região Centro-Oeste, cuja predominância até então se voltava às regiões Sul e Sudeste (BACARJ et al., 2007). Em 2011, Mato Grosso do Sul já tinha 250 propriedades assistidas pelo Projeto Balde Cheio e 90 técnicos treinados.

\section{DIÁLOGOS COM A LITERATURA}

No caso estudado, a escala municipal é muito restrita para a promoção do desenvolvimento da cadeia leiteira, e a escala estadual é excessivamente ampla para dar conta da heterogeneidade e das especificidades locais. Portanto a bacia leiteira é a unidade que melhor dimensiona os laços de proximidade entre pessoas, grupos sociais e instituições que podem estabelecer iniciativas voltadas ao desenvolvimento de um APL. Além disso, tendo como finalidade o reordenamento agrário, a subdivisão do Estado em bacias leiterias colabora para a ampliação das capacidades humanas, institucionais e da autogestão das bacias. Fato esse que, teoricamente, poderia estimular as relações de confiança e cooperação na formação do APL.

É importante destacar a importância do protagonismo dos atores participantes de cada bacia, o que possibilita a abertura de amplos espaços de participação, autogestão e descentralização das decisões na formulação, execução e controle social das ações que compõem as estratégias de política pública. Há, da parte do Governo do Estado, muito entusiasmo com o Projeto Balde Cheio em Mato Grosso do Sul, o que representa uma oportunidade de ampliação de políticas públicas e de apoio administrativo e financeiro. De acordo com o Ministério do Desenvolvimento Agrário (MDA) (BRASIL, 2005a; 2005b), experiências bem sucedidas de desenvolvimento rural 
caracterizam-se sistematicamente pela ampliação do círculo de relações sociais, socioeconômicas e sociopolíticas, ou seja, de uma ampliação das relações entre os atores.

Para uma visão integradora de APL é preciso criar condições para que os agentes locais diagnostiquem suas potencialidades e restrições, a fim de promover um desenvolvimento da região. Além disso, os processos de formação de APL envolvem desde a geração de trabalho e renda, a melhoria da qualidade de vida das populações, o exercício da cidadania, até a compreensão do meio ambiente como essencial à atividade produtiva. Os produtores rurais envolvidos no Projeto Balde Cheio são agricultores familiares e beneficiários da Reforma Agrária. A grande maioria deles tem propriedade com cerca de 28 hectares, onde o desenvolvimento de culturas como a soja, o milho e até a pecuária de corte tornam-se inviáveis economicamente. Assim, as autoridades locais e os próprios produtores rurais buscaram, na pecuária leiteira, uma alternativa para incrementar a renda das famílias assentadas e, em seguida, com a implantação do Projeto Balde Cheio, tornar a atividade um meio de vida. Há uma adequação do Projeto à realidade e às especificidades das comunidades locais para que a proposição de inovações seja capaz de alavancar a produção leiteira no Estado.

Em Sidrolândia, estava prevista, para 2011, a instalação da agroindústria de leite em pó Lactis. A empresa iria consumir cerca de 250 mil litros de leite por dia, e seriam fechados contratos de fornecimento com 300 agricultores familiares. Eles receberiam assistência técnica com adoção das técnicas do Projeto Balde Cheio. No entanto o município não conseguiu atrair a empresa para a cidade. Dessa maneira, em relação à comercialização, vale considerar que a agroindústria poderia proporcionar um equilíbrio entre a oferta e a demanda do produto na região. Isso faria aumentar a oferta de emprego na região, a arrecadação de tributos do município e o fortalecimento do comércio local.

Outro agravante é que o único laticínio do município parou de funcionar em agosto de 2014, restando aos agricultores comercializar seu produto às indústrias de Campo Grande e Terenos, as quais muitas vezes impõem preços mais baixos ao leite, pelo gasto com o transporte até o município. Frente a isso, pode-se dizer que o setor público municipal tem deixado a desejar principalmente no auxílio à comercialização do leite produzido no município, fato que dificulta o desenvolvimento de um APL.

O APL também depende de um conjunto de relações que podem ser mobilizadas visando a um determinado fim, baseado na confiança, reciprocidade e cooperação. Vale lembrar que poucos agricultores do Estado são vinculados a associações ou cooperativas para comercialização de leite, mas a grande maioria deles é filiado ao Movimento dos Trabalhadores Rurais Sem Terra (MST) e à Federação dos Trabalhadores na Agricultura (FETAGRI), ou seja, pertencem a algum tipo de entidade representativa centrada na agricultura familiar.

Por fim, além dessas entidades, a FAMASUL, a SEPROTUR e o Incra aparecem como uma instância intermediária do Governo do Estado entre o governo federal e os municípios. A governança, que tem papel primordial em um APL, pode ser entendida como as relações entre os atores sociais e políticos. Desse modo, pode-se verificar que, além de servirem como veículo de captação de demandas locais, há a preocupação de promover uma articulação intermunicipal para a implementação dos programas governamentais através das ações dos extensionistas da AGRAER. O Projeto Balde Cheio recebe o apoio do Governo do Estado para que a assistência técnica seja contínua e de qualidade. Para isso, ele tem promovido a estruturação da cadeia do leite no Estado, por meio de patrulhas mecanizadas, resfriadores de leite, ordenhadeiras mecâ- 
nicas, kit irrigação e de sanidade, além de eventos de capacitação continuada para os técnicos e produtores. Há ainda a participação do Serviço Nacional de Aprendizagem Rural (SENAR) e Serviço Brasileiro de Apoio às Micro e Pequenas Empresas (SEBRAE) estaduais na orientação e capacitação técnica dos produtores e extensionistas.

Desse modo, tanto produtores rurais quanto extensionistas, laticinistas e consumidores locais devem dividir responsabilidades e direitos e serem capazes de confluir suas perspectivas individuais. No Estado, a produção de leite vem recebendo atenção especial das prefeituras municipais e dos diversos atores locais. Há uma consciência coletiva sobre a importância e a necessidade de potencializar e modernizar a atividade.

A melhoria na produtividade estimula a fixação das famílias no meio rural e, consequentemente, promove melhorias na qualidade de vida, autoestima e valorização humana, além da sustentabilidade da economia municipal e regional e melhor distribuição de renda na região. Em São Gabriel do Oeste, município participante do Projeto, os produtores conseguiram elevar a produtividade em suas propriedades de 35 para 120 litros diários de leite (DIÁRIO MS, 2014). Em 2012, um produtor rural de Sidrolândia conseguiu elevar a produção do seu rebanho de 14 vacas leiteiras de 60 para 220 litros diários de leite. Em 2014, o produtor já contava com 20 vacas e uma produção diária de 358 litros de leite (PAES, 2012; 2014). O que mudou em ambos os casos foi o manejo e a adoção de tecnologia. No passado, o alimento aos animais vinha exclusivamente de um pasto de má qualidade. Após a implantação do Projeto, as vacas passaram a se alimentar também de ração. A irrigação do pasto, também viabilizada pelo Projeto por meio de kits de irrigação, garante alimento o ano inteiro e produtividade alta, além de um melhor aproveitamento da propriedade, que é dividida em piquetes.

No Projeto Balde Cheio, o melhoramento animal, a melhoria da pastagem, com adubação e irrigação, a rotação de animais na área, a melhoria genética e a qualidade da alimentação dos animais trazem, além de melhoria de renda, a superação da pobreza e a garantia da segurança alimentar aos envolvidos no Projeto. Além disso, a participação do SENAR do SEBRAE no Projeto seria um exemplo do incentivo à educação local, visto que estes proporcionam capacitações que vão desde o manejo da ordenha, qualidade do leite, alimentação dos animais até consultorias em gestão empresarial, empreendedorismo e organização social. Essas ações vêm apresentando bons resultados, conforme exposto anteriormente, embora o Projeto ainda esteja restrito a poucas propriedades tanto em Sidrolândia quanto no restante do Estado.

O objetivo ao qual o Projeto Balde Cheio se propõe ainda não foi completamente alcançado, mesmo que muitas conquistas e ações já tenham sido feitas. Isso porque, conforme já mencionado, poucos produtores rurais do Projeto são organizados em associações ou cooperativas, por exemplo. Além disso, eles não dividem equipamentos como resfriadores e implementos agrícolas. Cada produtor necessita ter o seu equipamento, o que pode encarecer o custo inicial de implantação da atividade. No mais, pela ausência de entidades que os representem, eles têm pouco poder de negociação de preços e condições de pagamentos junto aos laticínios da região. Além disso, é importante salientar que a iniciativa da implantação do Projeto no Estado partiu do Governo do Estado e dos municípios, e não dos produtores rurais da região.

Consequentemente, é necessário ainda fortalecer as estratégias que incentivem a ação social conjunta, o acesso igualitário aos recursos locais, o respeito e a preservação do meio ambiente, bem como o respeito à cultura local. Torna-se fundamental que os produtores inseridos no Projeto tenham acesso ao conhecimento técnico e de mercado da atividade leiteira para que os recursos sejam empregados com cautela. 
Desse modo, pode-se dizer que o Projeto Balde Cheio em Mato Grosso do Sul apresenta poucos elementos que podem direcionar para um APL. Isto porque pôde ser observado que, apesar de, no Projeto, haver o objetivo de estimular uma atividade local com potencial na região, há efetivamente pouco envolvimento do setor público na melhoria da comercialização do produto, por exemplo. No entanto o Projeto Balde Cheio estimulou a formação de um subprojeto exclusivamente estadual para o desenvolvimento da cadeia produtiva do leite, o Leite Forte MS. Não se conhecem os objetivos deste projeto nem o porquê da criação de um projeto paralelo ao Balde Cheio, porém há indícios de uma maior autonomia do Estado na gerência dos recursos financeiros e humanos nesse projeto.

O Projeto Balde Cheio possui uma estrutura para transferência de tecnologia na qual capacita os extensionistas, acompanha as propriedades denominadas Unidades de Demonstração que são utilizadas como "salas de aula", e os extensionistas capacitados assistem outras propriedades da região transferindo dessa forma tecnologia e elevando a capilaridade dos projetos. Em muitas propriedades em Sidrolândia, o melhor uso da terra resultou em expressivo ganho de produtividade e resgate de autoestima e dignidade do pequeno produtor. No entanto, para participar do Projeto, é necessário realizar investimentos, adaptação a um novo modelo de gestão, aceitar sugestões e receber visitas periódicas de avaliação em suas propriedades, o que nem sempre é bem recebido.

\section{CONSIDERAÇÕES FINAIS}

Para a consolidação de um APL, primeiramente ele precisa ser composto por entidades representativas dos mais variados segmentos, desde os produtores rurais, que são a base de sustentação do APL, até as indústrias, as associações e o poder público. Não obstante, eles precisam se relacionar, estar bem integrados e compartilhar valores e interesses comuns.

Assim, saber se há e de que forma essas relações estão presentes é de fundamental importância. Isso indica ao Projeto onde há fragilidades e as maiores potencialidades que precisam ser desenvolvidas para estimular a consolidação de um APL.

O Projeto Balde Cheio apresenta algumas fragilidades que precisam ser minimizadas para a consolidação de um APL em Mato Grosso do Sul e para o desenvolvimento local: ele poderia concentrar algumas de suas ações em atividades que objetivem estreitar as relações com os produtores a fim de obter deles as reais necessidades e propor melhorias ao setor, por exemplo. Além disso, às instâncias municipal, estadual e federal caberia buscar melhorias na infraestrutura logística do meio rural, a fim de melhorar as condições de comercialização do leite desses produtores. No mais, a formação de cooperativas e associações, que poderiam servir de elo entre os diversos setores do APL, precisa ser estimulada pelo poder público, uma vez que elas podem auxiliar também na assistência técnica e prestação de contas e serviços. Ações como essas e desenvolvidas em conjunto partilham confiança e cooperação e precisam de continuidade. Por isso, a realização de seminários, dias de campo e feiras relacionadas à produção de leite poderiam oportunizar a troca de informações entre os produtores e as indústrias de leite do Estado. Isso oportunizaria também a possibilidade de negociação dos preços pagos pelo leite aos produtores, em troca do atendimento aos padrões de qualidade higiênico-sanitários exigidos pelos laticínios.

Apesar dessas fragilidades, alguns elementos já presentes no Projeto podem servir como uma política de estímulo à consolidação do APL. São eles: o potencial do Estado para 
o desenvolvimento da atividade; o fato de grande parte da produção de leite do Estado já vir da agricultura familiar; já existir uma divisão do Estado em bacias leiteiras e isso favorecer o conhecimento do nível de tecnologia empregado pelos produtores e dos locais de comercialização do produto; a disponibilidade de orientação e capacitação técnica (AGRAER, SEBRAE e SENAI); o apoio administrativo e financeiro do Governo do Estado; os resultados (aumento da produção e da produtividade de leite) aparecem no curto prazo aos participantes do Projeto, o que serve de incentivo para continuarem participando e de estímulo aos que ainda não participam do Projeto.

Desse modo, compreende-se, de acordo com a pesquisa realizada, que a existência de fragilidades e potencialidades pode contribuir para a formação e a consolidação de um APL em Mato Grosso do Sul. Muitos serão os desafios que os envolvidos no Projeto encontrarão para transformar suas ações em práticas mais consistentes que visem ao desenvolvimento local e à consolidação do APL. Faz-se necessário realizar outras investigações para ampliação das discussões em torno dos fenômenos analisados como, por exemplo, o estudo do mesmo caso no futuro, quando podem se manifestar novas necessidades e transformações na realidade institucional social, política, econômica e cultural dos participantes e do projeto analisado. Pesquisar políticas de incentivo à formação de arranjos locais a partir de habilidades como governança e capital social, refletindo sobre seus desdobramentos para o desenvolvimento local de territórios, parece ser uma articulação teórica relevante para o debate sobre a gestão de políticas públicas no contexto brasileiro. Nesse aspecto, novas pesquisas sobre o tema são bem-vindas e podem, além de oferecer novas perspectivas para essa revisão crítica, avançar na mensuração dos resultados do Projeto no Estado, como uma pesquisa a campo, com o intuito de dialogar com os participantes do Projeto e avaliar a evolução do Projeto Balde Cheio em Mato Grosso do Sul.

\section{Agradecimento}

Os autores gostariam de agradecer o auxílio e as contribuições do pesquisador da AGRAER de Mato Grosso do Sul, Victor Corrêa de Oliveira, do coordenador regional do Projeto, Ivan Macena, e do então secretário do Desenvolvimento Rural e Meio Ambiente de Sidrolândia, Nilo Cervo, nas informações para a construção deste artigo.

\section{REFERÊNCIAS}

AMATO NETO, J. Gestão de sistemas locais de produção e inovação: Clusters/APLs. São Paulo: Atlas, 2009.

BACARJI, A. G.; HALL, R. J.; ZANON, H. Os impactos da sazonalidade da produção de leite numa indústria de laticínio no Estado de Mato Grosso do Sul. In: SIMPÓSIO DE EXCELÊNCIA EM GESTÃO E TECNOLOGIA (SEGeT), 4., 22 a 24 out. 2007, Resende, RJ. Anais... Resende: Associação Educacional Dom Bosco, 2007. p. 1-15.

BACARJI, A. G.; SAUER, L. A atuação das organizações da câmara setorial da cadeia produtiva do leite na garantia da qualidade do produto em Mato Grosso do Sul. Organizações Rurais \& Agroindustriais, Lavras, MG, v. 13, n. 2, p. 201-13, 2011.

BRASIL. Ministério do Desenvolvimento Agrário (MDA). Marco referencial para apoio ao desenvolvimento de territórios rurais. Brasília, DF: MDA, 2005a.

Ministério do Desenvolvimento Agrário (MDA). Referências para uma estratégia de desenvolvimento rural sustentável no Brasil. Brasília, DF: MDA, 2005b. 
BÜTTENBENDER, P. L. Arranjos institucionais, cooperação e desenvolvimento - redes econômicas, tecnológicas e sociais: sementes do desenvolvimento agregando valor. Ijuí, RS: Ed. Unijuí, 2010.

COSTA, A. B.; COSTA, B. M. Cooperação e capital social em arranjos produtivos locais. In: ENCONTRO NACIONAL DE ECONOMIA (ANPEC), 33., 2005, Natal, RN. Anais... Natal, RN: ANPEC, 2005.

EMPRESA BRASILEIRA DE PESQUISA AGROPECUÁRIA (EMBRAPA). Pecuária Sudeste. Projeto Balde Cheio: tecnologias que agregam valor à produção de leite. 2011. [Folder]. Disponível em: <http://www.cppse. embrapa.br/sites/default/files/principal/publicacao/baldecheio0712.pdf>. Acesso em: 15 jan. 2016.

INOVAÇÕES tecnológicas na produção leiteira são apresentadas a agricultores familiares em Caarapó. Diário MS, Dourados, MS, 29 mar. 2014. Disponível em: <http://diarioms.com.br/inovacoes-tecnologicasna-producao-leiteira-sao-apresentadas-a-agricultores-familiares-em-caarapo/>. Acesso em: 15 jan. 2016.

INSTITUTO BRASILEIRO DE GEOGRAFIA E ESTATístICA (IBGE). Produção da Pecuária Municipal. 2014. Disponível em: <http://ibge.gov.br>. Acesso em: 15 dez. 2016.

Censo Agropecuário 2006. Rio de Janeiro: Ministério do Planejamento, Orçamento e Gestão, 2009. p. 1-777.

LASTRES, H. M.M.; CASSIOLATO, J. E. (Coord.). Glossário de arranjos e sistemas produtivos e inovativos locais. Arranjos produtivos locais: uma nova estratégia de ação para o SEBRAE. Rio de janeiro: UFRJ, nov. 2003.

MATO GROSSO DO SUL. Secretaria de Estado de Meio Ambiente, Desenvolvimento Econômico, Produção e Agricultura Familiar (SEMAGRO). Bacias leiteiras no MS. [s.d.]. Disponível em: <http://www.semagro. ms.gov.br/camaras-setoriais/camara-setorial-da-cadeia-produtiva-do-leite-de-mato-grosso-do-sul/>. Acesso em: 31 ago. 2017.

MICHELS, I. L. et al. Estudo das cadeias produtivas de Mato Grosso do Sul: leite. In: MICHELS, I. L. (Coord.). Estudo das cadeias produtivas de Mato Grosso do Sul. Campo Grande, MS: Oeste, 2003.

NORONHA, E. G.; TURCHI, L. Política industrial e ambiente institucional na análise de arranjos produtivos locais. Brasília: Ipea, 2005.

PAES, F. Assentamento modelo na produção leiteira ganha patrulha e kit de irrigação, ordenhadeira e resfriador. Região News, 27 jan. 2014. Disponível em: < http://www.regiaonews.com.br/noticias/166075/ Assentamento-modelo-na-producao-leiteira-ganha-patrulha-mecanizada--Leia.html>. Acesso em: 15 jan. 2016.

Com balde cheio, assentado aumenta em 220\% produção de leite. Região News, 9 abr. 2012. Disponível em: <http://www.regiaonews.com.br/noticias/134769/-b-Com-balde-cheio--assentadoaumenta-em-220--producao-de-leite--b-.html>. Acesso em: 15 jan. 2016.

RIBEIRO, K. A., NASCIMENTO, D. C, JUNIOR, N. F. C, MORATO, J. A. Q. Arranjo produtivo local (APL) como estratégia de potencializar as fronteiras mercadológicas do apicultor no perímetro de irrigação Senador Nilo Coelho em Petrolina-PE. Revista de Gestão, Finanças e Contabilidade, UNEB, Salvador, v. 3, n. 2, p. 99-120, 2013.

SIMÕES, A. R. P. Contexto social e tecnológico da cadeia produtiva do leite no MS. 2009. [curso ministrado, de curta duração]. 


\section{Sobre os autores:}

Lilian Cervo Cabrera: Doutora em Agronegócios pela Universidade Federal do Rio Grande do Sul, mestra em Extensão Rural, jornalista e engenheira agrônoma pela Universidade Federal de Santa Maria. E-mail: liliancabrera_86@yahoo.com.br

Glauco Schultz: Doutor e mestre em Agronegócios pela Universidade Federal do Rio Grande do Sul, engenheiro agrícola pela Universidade Federal de Pelotas. Professor Adjunto da Faculdade de Ciências Econômicas e do Centro de Estudos e Pesquisas em Agronegócios na Universidade Federal do Rio Grande do Sul. E-mail: glauco.schultz@ufrgs.br

Edson Talamini: Doutor e mestre em Agronegócios pela Universidade Federal do Rio Grande do Sul, economista pela Universidade de Passo Fundo. Professor Associado da Faculdade de Ciências Econômicas e do Centro de Estudos e Pesquisas em Agronegócios na Universidade Federal do Rio Grande do Sul. E-mail: edson.talamini@ufrgs.br 